The 1943 reports of the German rocket activity led the US Army Ordnance Department to enter into a contract with Caltech for the continued operation of JPL, under which JPL would develop artillery-type ballistic missiles. This effort continued into the Cold War period, and from it emerged the Corporal E liquid-propellant missile and the Sergeant solid-propellant weapon, both of which were eventually deployed in Europe. The latter was the forerunner of the modern Pershing missiles. The anxiety of the government to get these weapons into production as quickly as possible caused much confusion and frustration at JPL. Yet in this period the laboratory learned much about system analysis and development, and also took the first, crucial steps towards creating what ultimately became a spectacularly successful system of electronic guidance, control and communication for missiles and spacecraft.

This missile research was terminated with the appearance of Sputnik and the initiation, in 1958, of the US space programme, managed by a new civilian agency, the National Aeronautics and Space Administration (NASA), which took over the JPL contract. Caltech and JPL were glad to close their secret military weapons programme and to engage in a more scientifically rewarding enterprise. Spectacular managerial problems among the administrators within the Caltech-JPL-NASA triangle, all of which are fully described by Dr Koppes. This was the era, however, in which the appellation "National Security State" seems to have the least relevance, even though the Caitech-JPL-NASA relations were at their most difficult. The problems stemmed, not from security considerations, but from the policy of NASA to monitor most critically every aspect of the performance of JPL, at a time when that establishment was tackling the most challenging problems in its history.

It was ironic that just when Viking and Voyager projects brought JPL to the peak of its prestige, the government began to cut back on planetary exploration, partly because the Space Shuttle programme was soaking up such a large proportion of the NASA budget. JPL suffered serious setbacks when the US portion of the International Solar Polar mission was cancelled, as well as the proposed fly-by to Halley's comet. The only new project remaining for JPL is the Galileo mission to Jupiter, carrying a probe to be released into Jupiter's atmosphere.

Galileo, the future space telescope and other scientific instruments are to be carried on the Space Shuttle, along with a variety of secret military payloads. This im-

\section{Schemes and dreams of fusion}

\author{
Philip Davenport
}

Fusion: Science, Politics, and the

Invention of a New Energy Source.

By Jean Lisa Bromberg.

MIT Press: 1982. Pp.343. \$30, £24

CONTROLLED thermonuclear research (CTR) has as its primary goal the demonstration that nuclear fusion reactions between light elements can provide us with a new and benign energy source. But despite over 30 years of steadily expanding endeavour by many countries, now freely collaborating, this goal still eludes us. Opening the first International Conference on the Peaceful Uses of Atomic Energy in 1955 , when the subject was still classified as secret by the nuclear powers, Homi J. Bhabha of India predicted, "a method will be found for liberating fusion energy in a controlled manner within the next two decades". Much the same might be said today.

This situation, though favourable for the job prospects of plasma physicists, puts the historian in a quandary; any account of a national fusion programme must necessarily be open-ended - should one wait for a successful outcome to round it off neatly? The answer is an actuarial no; several pioneers of fusion have already died - Thomson, Cockcroft and Chick in Britain, Kurchatov, Sinelnikov and Artsimovich in Russia, and Ruark, Christofilos and Tuck in the United States. (Fortunately Dr Bromberg started her work in good time to interview Tuck.) Others candidly admit to having memories that are dulled or, more embarrassing, inventive; the historian has little time to spare.

As the subtitle of her book suggests, Joan Bromberg has concentrated on the political and organizational aspects of the Magnetic Fusion Program in the United States, while providing just the right amount of scientific background and detail to enable the non-specialist reader to understand the principles of the various experimental approaches described. The result is a fascinating account of how the development of one governmentsponsored research project has been shaped by scientists, politicians, industrialists and world events.

Experimental work on CTR began quietly in Britain in the late 1940s, with a total of about a dozen scientists working in three small groups at the universities of Oxford, London and Liverpool. Although this work received no publicity, quite a few physicists knew about it; significantly, these included James Tuck, working at Oxford, and Klaus Fuchs at Harwell. Tuck moved to the United States in 1949, became naturalized, and initiated the fusion programme at Los Alamos which later became
Lee A. DuBridge, a member of the President's Science Advisory Committee from 1969 to 1972 was President of Caltech from 1946 to 1969 where he is now President Emeritus. 
known as Project Sherwood. Fuchs took a different direction. In March 1950 he was convicted of spying for Russia, and towards the end of that year CTR in the UK was classified as secret, ostensibly because of its military potential. In my view the real reason was an obsession with secrecy for its own sake, to which the United States Government was not immune, for their fusion programme was born classified in spite of concerted opposition from the scientists concerned. Even the very fact that the Atomic Energy Commission was sponsoring CTR was kept secret, as was the location of the experiments, although all three countries must have been aware of each other's interest in CTR. Surprisingly Russia was the first to publicize its fusion research through the famous Kurchatov lecture at Harwell in 1956, much to the discomfiture of the other two.

Subsequently the security barriers were gradually dismantled. First came the UKUS exchanges of information and laboratory visits. Then, after some hard bargaining in an atmosphere of rivalry and

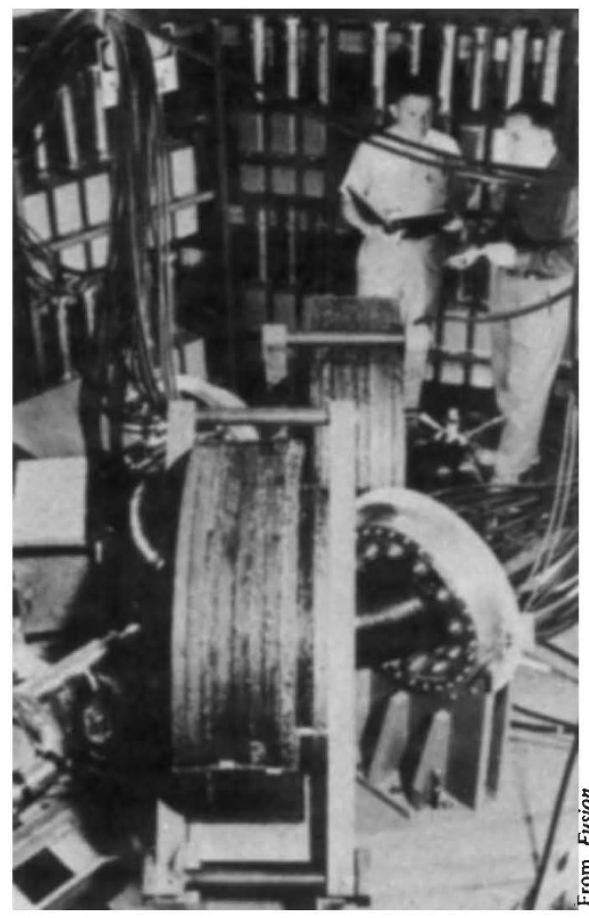

Los Alamos's Perhapsatron S-4, which together with other examples of fusion technology was displayed at the second Geneva Conference in 1958.

suspicion fomented by the Press on both sides of the Atlantic, agreement was reached on the publication in Nature in January 1958 of a group of papers which in effect formed a joint progress report on CTR. Bromberg's account of this episode may upset the more sensitive members of the Harwell team even now, and indeed it does contain some technical inaccuracies concerning ZETA, the huge toroidal gas discharge which was Britain's major fusion experiment. But in the context of a history of fusion within the United States, it is in my view a valid and objective assessment of a precarious period in UK-US collaboration.
Complete declassification of CTR was agreed in time for the second Geneva Conference in 1958, where all nations having fusion programmes would be able to reveal the extent of their progress and to exchange ideas. Here the Americans took the opportunity to mount an elaborate working exhibit, the Sherwood Spectacular, which dominated the conference and attracted 100,000 visitors. This was a great boost to US prestige, but it was only achieved at the cost of totally diverting their CTR effort for many months.

The account of the first decade of fusion work in the United States is for me the most interesting part of the book. The four government-sponsored laboratories Livermore, Los Alamos, Oak Ridge and Princeton - enjoyed a high degree of autonomy. They worked on their individual ideas with a pioneering and sometimes partisan attitude in geographical isolation; a round trip of these laboratories entailed a journey of at least 6,000 miles. This is reflected in the diversity of their early schemes for the magnetic confinement of plasma, some of which bore intriguing names. Los Alamos had its Perhapsatron and Columbus, pulsed discharges in toroidal and cylindrical tubes respectively; Livermore had magnetic mirror traps named Toy Top and Table Top; Princeton's large pretzel-shaped apparatus was called the Stellarator. Oak Ridge's direct current experiment had the more prosaic acronym, DCX. Naming fusion devices gave much scope for whimsical originality; my favourite acronym is Llandudno - large linear and no doubt unstable discharge - coined by Tony Malein at Harwell.

With the advent of international cooperation in CTR, the US experimental programme became increasingly influenced by developments overseas. Over the same period scientific direction and financial control were inexorably withdrawn from the laboratories to the central administration in Washington DC. The later chapters of the book mainly deal with the activities of this central power base under changing styles of leadership and organization. They provide an insight into the vagaries of political priorities and industrial expediency which is instructive and at times cautionary.

This book is, as far as I am aware, the first official history of a national fusion programme to be published. Earlier accounts of fusion research have in the main been written by participants rather than professional historians, and in consequence have been restricted in scope and outlook. Joan Bromberg has set high standards of sensitive objectivity, technical exposition and assiduous referencing for others to follow.

Philip Davenport joined the CTR group at Oxford in 1949 and subsequently worked on early experiments at Harwell and Culham Laboratory. Now retired, he is an honorary consultant to Culham on historical matters.

\section{Style of a physicist}

R.H. Dalitz

Tabibito (The Traveler).

By Hideki Yukawa.

World Scientific/Wiley: 1982. Pp.218.

Hbk $£ 22.50, \$ 38 ; p b k$ f11, \$19.

As a person, Hideki Yukawa was little known in Western countries, although he died only two years ago. His name, however, won international renown for his theory that the nuclear forces were mediated by a field due to massive meson, as laid out in his paper of November 1934 published in the Proceedings of the Physico-Mathematical Society of Japan, for which he received the Nobel prize in 1949. This autobiography, detailing his life from his birth in 1907 up to 1934 and telling how he came to his idea, has therefore a rather special interest.

The first surprise is to learn that Yukawa was his adoptive surname, taken when he married into the Yukawa family. His father's surname was Ogawa, but that again was an adoptive surname, for his paternal grandfather's surname was Isai. To confuse things further, his father-inlaw was born with the surname Sakabe. His father-in-law's adoption by the Yukawa family had a more understandable, although surprising reason, namely that the family Sakabe had been abolished by a local Lord, who ordered Sakabe senior to commit hara-kiri, so that Sakabe junior was in need of a family.

Despite this unfamiliar background, Yukawa's mind and its course of development conform to patterns quite familiar to us, common among physicists of imagination. The young Yukawa was strongly introverted and his inner life was the more immediate and dominant for him, until well into his late 20s. Much he considers important about his childhood goes against current educational theories. For example, his grandfather taught him the Chinese symbols by rote, introducing him to the great Chinese classics without any understanding of the text in which they were used, a training he counted a great advantage in later life. He also found great value in children's literature of an old-fashioned type which taught him important patterns of behaviour and provided models for his attitudes in life. As he put it, "the chaotic material" which came into his mind in this way "became ordered and organized into life's direction".

Yukawa had no yearning for foreign lands; his life was mostly within him. When Einstein came to Kyoto to lecture, he made no effort to attend (although he was, of course, then only in high school and did not know that he was to become a physicist). However, Yukawa's interest in modern physics was first aroused about this time, by Reiche's book on the old quantum theory and its difficulties, which he found 